\title{
Research on Methods and Contents of Collecting Data for Urban Master Planning in China
}

\author{
Jie Shen \\ School of Urban Construction \\ Wuhan University of Science and Technology \\ Wuhan, China \\ Email: 675493824@qq.com \\ Shuanghui Sun \\ Hubei Institute of Urban Planning and Design \\ Wuhan, China \\ Email:23023196@qq.com
}

\author{
Haiying Wang \\ Hubei Institute of Urban Planning and Design \\ Wuhan, China \\ Email: 64342154@qq.com
}

\begin{abstract}
Data collection has always been the basis of planning, and only an informative basic data survey can be used for reasonable planning. The collection of basic data on urban planning was officially promulgated in 2012 in the form of national standard, "Code for the Collection of Basic Data for Urban Planning" (GB/T50831-2012). The city's overall planning, control detailed planning, constructive detailed planning and contents of the collection of basic data is collected from the basic data to make an overall request. However, there is no specific and normative requirement for the assessment implementation of the urban overall planning. There will be some confusion for the colleagues who have just joined the work. This article is based on the author's work experience, and hopes to provide some reference to some of the peers who have just joined the work and have not yet collected any information in the basic data collection stage.
\end{abstract}

Keywords: overall urban planning, compile information, collection

\section{INTRODUCTION}

The evaluation of the implementation of the urban overall planning can be traced back to Article 20 of the "Regulations on Urban Planning" promulgated by the State Council in 1984. The regulations state that "the urban people's government should regularly check the implementation of the overall urban planning and report to the city's People's Congress or its Standing Committee and Ratifying Authority every five years.",which can be used as an early legal provision for the implementation of the urban overall planning.

The evaluation of the implementation of the city's master plan has officially entered the task of preparing the majority of planners for eight years. However, what basic information needs to be collected for the implementation assessment has not yet been stipulated by the state and industry norms, and it is still blank, which brings us some confusion in the free implementation evaluation. Whether the preparation of the free-form implementation assessment report needs to be based on the requirements of the "Code for the Collection of Basic Data for Urban Planning" (GB/T50831-2012) and the collection of basic data for dozens of departments in the county according to the requirements of the overall planning of the city are worthy of consideration by our planners. The seemingly simple problem is indeed neglected in our daily work. For those who have just joined the work, they are faced with the preparation of a free-style implementation assessment and they have no basis for what basic information they need to collect. Through the work experience accumulated in the actual preparation of the urban master plan implementation assessment, the author sorts out the necessary basic data for the implementation assessment, and hopes to provide some reference for the compilers who carry out the free implementation assessment. Next, the author will briefly talk about some superficial understandings of the basic data collection of urban master plan implementation assessment.

\section{II.SOME UNDERSTANDINGS ON THE IMPLEMENTATION EVALUATION OF URBAN MASTER PLAN}

\section{A. Current Trends in Implementing Assessments}

\section{1) Transition from bundled assessment to freestyle} assessment

With the gradual enhancement of local government's planning management awareness, free-form implementation assessments have emerged in recent years. The free-style implementation assessment is divided into two stages: implementation assessment and new round of urban master planning. That is, it is not an assessment based on the need to initiate a new round of urban master plan revisions, but a local government that needs to check the implementation of the current urban master plan for an active implementation assessment, which is bottom-up. In a certain sense, the free-style assessment is the focus of the compilation body on the implementation of the assessment work. It is a serious implementation of the "Measures for the Implementation of the Urban Master Plan (Trial)", which reflects to a certain extent that the local government is more standardized and ruled by law in planning and management.

2) Implementation evaluation level is gradually improved. 
Regarding the assessment of the urban master planning stage, the "People's Republic of China Urban and Rural Planning Law" and the "Measures for the Implementation of the Urban Master Plan Implementation (Trial)" have clear requirements, and the legal status of the urban master plan assessment is established from the legal level. There is currently no way to request an assessment of other types of planning, such as controlled detailed planning. In some areas, the bottom-up evaluation system was explored. Xiong Bin introduced the evaluation framework of control detailed planning assessment with his own practical work. Lin Liwei and Shen Shan introduced the development status of the evaluation system construction in urban design, near-term construction planning, urban transportation, and logistics planning. It can be seen that the current assessment system has formed a vertical evaluation system of "overall planning - controlled detailed planning + special planning".

\section{B. Characteristics of Freestyle Implementation Assessment Basic Data Collection}

\section{1) No separate specification for basic data collection}

What basic data need to be collected for the compilation of the overall urban planning can be collected and sorted according to the "Code for the Collection of Basic Data for Urban Planning" (GB/T50831-2012). However, what information needs to be collected for the implementation of the urban master plan assessment, there is currently no standard to follow. It is worth pondering whether we need to collect dozens of departments like the master plan for the preparation of the city.

2) Insufficient attention to basic data collection

At present, there are still insufficient problems in the collection of basic data for implementation evaluation, such as the lack of data in some years and the lack of sufficient basis for dynamic evaluation. Only a detailed assessment of the implementation of basic data can truly reflect the changes in the city in various aspects since the implementation of the overall planning of the city, and the deviation from the current urban master plan, whether it is necessary to restart a new round of urban master plan revision

3) Relatively few departments involved in the collection of basic data.

Compared with the basic data collection units involved in the preparation of the urban master plan, the units for freely implementing the basic data for evaluation are relatively few, and some functional units do not need to collect. Mainly because the preparation of a new round of urban master plan involves new urban construction land, it is necessary to understand the land use and geological conditions of the newly added areas. This requires a main collection of the Bureau of Land and Resources and the Bureau of Surveying and Mapping. The Seismic Bureau, the Meteorological Bureau, and the Local Records Office have basically kept the basic information in a certain historical period, and they are not involved in the implementation evaluation, so they do not need to be collected.

\section{IMPLEMENTATION ASSESSMENT BASIC DATA COLLECTION}

\section{A. Macroconomic}

The basic data collection of macroeconomics is mainly to complete the implementation of the implementation of the phased objectives in the assessment and the evaluation of planning management. In the implementation of the phased objectives, the implementation of urban development goals, industrial development direction and spatial layout, population and urbanization development level, urban scale, urban spatial structure, urban function guidance, and urban nature are evaluated. The content of these assessments specifically involves development, reform, statistics, family planning, public security, government offices and other departments.

\section{1) Development and Reform Department}

The basic information involved in the implementation of the evaluation phase of the Development and Reform Department is mainly the five-year plan for national economic and social development. The main purpose of collecting this content is to assess whether the planning objectives, industrial economy, urban space and functional planning proposed in the five-year plan for national economic and social development in the region are consistent with the current urban master plan, and the existing deviations.

\section{2) Statistics Department}

The basic data collection of the Statistical Department is an implementation assessment of urban function guidance, industrial development and industrial space layout in the completion of urban development goals. The information collected in the Statistics Department includes two categories, one is demographic information; the other is economic information. Demographic information includes census data, labor transfer, and township cards. The economic information includes the production of food crops, the production of agricultural facilities, etc. and whether there is a deviation between the current industrial development status at the municipal level and the industrial development guidance proposed by the current urban master plan.

\section{3) Family Planning and Public Security Department}

The basic data collected by the family planning and public security departments are mainly population data, including the statistics of the floating population, the population data of the years since the implementation of the current urban master plan, the statistics of the population and its changes, and the analysis of the total population balance, including changes in the total population, immigration and removal, and temporary population.

\section{4) Government office}

The basic data collection of government offices mainly includes two categories, one is the government work report for each year since the implementation of the current urban master plan, and the other is the land, transportation, industry, environmental protection, population, finance, investment, etc. since the implementation of the current urban master plan. 
analysising the impact on the implementation of the plan. The government work report for each year is the basis for the dynamic implementation assessment. The government work report will have a summary and outlook on population, economy and urban construction in each year. Through the analysis of the government work report, we can clearly understand the development and changes of the city since the implementation of the current urban master plan, and can objectively and practically judge the implementation of the current urban master plan.

\section{B. Urban Construction}

\section{1) Planning Department}

The assessment of the basic data collection of the planning department in relation to the implementation of the urban master plan in the implementation assessment at the central urban level is related to whether it can truly reflect the implementation of the current urban master plan. The specific content collected by the planning department includes two aspects: one is the land grant situation in the central city since the implementation of the current urban master plan; the second is the preparation of the lower plan and related plans since the implementation of the current urban master plan. The collection of basic data of the planning department is the focus of the implementation of the evaluation.

\section{2) Construction Department}

\section{a) Construction Department}

Among the basic materials collected by the Construction Department, the Housing and Construction Bureau is the focus. Some municipal Housing and Construction Bureaus have more departments, real estate, project management, and urban management. This requires us to focus on collecting information when collecting information. For example, in the Housing Management Department, collect the construction of affordable housing and the development of commercial housing since the implementation of the current urban master plan, and collect statistical reports on urban construction and statistical reports on village construction in the Project Management Department. From these reports, you can clearly understand the urban and rural construction in each year since the implementation of the current urban master plan. The information collected by the department can be combined with the basic data collected by power companies, telecommunications companies, and water companies, and the basic data is more informative.

\section{b) Public Facilities Department}

The departments that collect basic information on public facilities include the New Culture and Sports Bureau, the Education Bureau, the Health Bureau, and the Civil Affairs Bureau. Although there are many departments involved in this part, if the red line of land after the implementation of the current urban master plan approval is well in the planning department, and the annual red line of new land use of various natures after the implementation of the overall plan is in place, the basis of this department Data collection is not required. Because the basic data collection of the New Culture and Sports
Bureau, the Education Bureau, the Health Bureau, and the Civil Affairs Bureau is mainly used for the comparative analysis of the land use layout in the implementation assessment, the information in this part is mainly reflected in the situation of newly approved land, and the red line of land used in the planning department has been collected.

\section{c) Infrastructure Department}

The implementation assessment of infrastructure mainly involves the Transportation Bureau, the power company, the water company, the telecommunications company, and the Urban Management Bureau. The departments involved here need to collect basic data, because these departments are not only independent facilities, such as passenger stations, substations, water plants, sewage treatment plants, landfills, etc. but also involves the construction of new roads, water supply pipelines, power lines, etc, which cannot be expressed solely on drawings, and can only be expressed by textual description.

\section{Ecosystem}

\section{1) Agriculture and Forestry Department}

The basic data collection departments involved in the agriculture and forestry sector include the Bureau of Forestry and the Forestry Bureau and the Bureau of Landscape Architecture may be a department of the Housing and Construction Bureau in some cities. This time, it is listed for the convenience of discussion, but in any case, the basic information collected is the same. The basic materials collected by the Bureau of Landscapes involve the construction of park green space, protective green space and squares. If the content of the planning department is comprehensive, the information of the garden department can be omitted, because the department is mainly involved in independent land occupation. The basic information collected by the Forestry Bureau is mainly used to assess the implementation of space control at the county level, which needs to be collected separately and cannot be omitted.

\section{2) Disaster Prevention Department}

The basic data collection of the disaster prevention department is different according to the situation in the area of the city. For example, in the mountainous city, the information on geological disasters is more important; the city is a national key air defense city, and its civil air defense data. It is even more important; the information collected in flood control planning is even more important in areas with abundant river water systems. The departments collected in the disaster prevention implementation assessment mainly involve the Fire Department, the Civil Defense Department, the Water Conservancy Department, and some departments of the National Land Department.

\section{CONCLUSION}

The accurate basic data collection is the premise and basis for the preparation of urban overall planning implementation assessment. Only accurate and informative basic data can guarantee the scientific and rationality of the implementation of assessment preparation. The author 
hopes that this article can provide a little reference for the vast urban planning peers in the urban planning field and let them clearly grasp the basic data collected for the implementation of the urban master plan implementation assessment, and to alleviate the confusion and troubles in the collection of the preliminary basic data.

\section{REFERENCES}

[1] Xiong Bin. Preliminary Study on the Construction of Evaluation System Based on Plan Implementation- Taking Changsha City Planning Evaluation Work as an Example[J]. China Urban Planning Annual Conference, 2010

[2] Lin Liwei, Shen Shan. Progress and Prospects of Urban Planning Evaluation in China[J].Shanghai Urban Planning,2009(6):14-17

[3] Shi Yuan. Zhou Liya. Preliminary Discussion on the Theory, Method and Framework of Planning Evaluation-Taking Shenzhen's Recent Construction Planning Practice as an Example. Urban Planning. 2008. No.246(6): 39-43 